\title{
Fruits and Vegetables Purchasing Attitudes in Turkey: Packaging and Loss Reduction
}

\author{
Derya Kocak Yanik (Corresponding author) \\ Engineering Faculty, Food Engineering Department, University of Gaziantep, \\ 27310 Gaziantep, Turkey \\ E-mail: dkocak@gantep.edu.tr \\ Aysel Elik \\ Engineering Faculty, Food Engineering Department, University of Gaziantep, \\ 27310 Gaziantep, Turkey \\ E-mail: aelik@gantep.edu.tr \\ Yildiray Istanbullu \\ Central Research Institute of Food and Feed Control, Ministry of Agriculture and Forestry, \\ 16036 Bursa, Turkey \\ E-mail: yildiray.istanbullu@tarimorman.gov.tr \\ Fahrettin Gogus \\ Engineering Faculty, Food Engineering Department, University of Gaziantep \\ 27310 Gaziantep, Turkey \\ E-mail: fahret@gantep.edu.tr
}

\begin{abstract}
The role of packaging cannot be underestimated in reducing the post-harvest losses of fresh fruits and vegetables. In this study, Turkish consumers' attitudes towards purchasing packaged fresh fruits and vegetables were examined by a structured survey of 623 urban respondents from all around Turkey. It was found that $69 \%$ of the respondents did not purchase packaged fresh fruits and vegetables at all. More than $50 \%$ of the respondents thought that packaging either protects fresh produce against impact or preserves the taste and freshness. While $40.52 \%$ of the respondents think that some of the loose fresh product they bought is not consumed and results in waste, only $23.27 \%$ of them think this for packaged fresh products. Strawberry was the most preferred fruit to be packaged among 10 different fresh products. Analyses of demographic variables revealed that there are no statistically significant differences among different consumer groups on their packaged fresh produce purchase routines, perception of attributes of the package, and the role of packaging on the reduction of waste.
\end{abstract}

Key words: Consumer Attitudes, Packaging, fresh produce, waste

DOI: $10.7176 / \mathrm{JSTR} / 6-08-05$

\section{Introduction}

Insufficiency of natural resources, climate changes and growing world population poses a serious risk for food security and sustainability. The studies conducted in recent years indicate that the world's population will reach 9 billion by the middle of this century and that agricultural land will be scarcer and poorer in quality (Gomiero et al., 2008). The world food production capacity will be effected from the growing competition for land, water, and energy (Godfray et al., 2010). This challenge requires urgent changes in the way of food producing, storage, distribution and consumption. At this point, food wastes and losses in food supply chain have become one of the most important issues of today's world.

Fruits and vegetables are an indispensable components of a healthy diet. The estimated postharvest losses of fresh fruits and vegetables are changing between 5 to $35 \%$ and 20 to $50 \%$ in developed and developing countries, respectively (Kader, 2002). Fruits and vegetables are highly perishable because of their high moisture content and delicate nature. The moisture loss, bruising, physical damage and subsequent decay are leading degradation types which responsible with disposal of fresh fruits and vegetables (Ray and

39 | $P$ a g e

www.iiste.org 
Ravi, 2005; Kitinoja, 2002). The large scales of postharvest losses are generated if the processing, storage, packaging and distribution conditions are not controlled properly. The packaging of fresh produce is one of the most important solutions to reduce the postharvest loss of them. The important functions of packaging are protecting and preserving of fresh produce, while also promoting hygiene and safety and facilitating transportation, storage and distribution from production stage to the consumer (Rundh, 2005). The positive effect of packaging on extending the shelf life of some fruits and vegetables have been reported in litrature. For instance, Shahnawaz (2012) reported that the fresh tomato have a short storage period, generally 2-3 weeks but concluded that tomatoes wrapped in polyethylene bags can enhance the shelf life upto 28 days. Additionally, Fagundes et al., (2015) have found that postharvest life of tomatoes can be increased up to 25 days due to lower respiration and ethylene production rate when it is packed in multilayer plastic bags. Kaewklin et. al. (2018) have indicated that the coating of fresh tomato with chitosan-titanium dioxide nanocomposite film or chitosan film have prevent fungal infection when compared it with uncoated fresh tomato. In another study it was observed that the fresh figs which packed with modified atmosphere packaging have kept its physical and chemical properties until 24 days and the weight loss was less than $1 \%$ for them after 42 days. However the shelf life of control was less than 14 days (Alturki et al., 2013). Koutsimanis et al., (2015) reported that the cherries packed in polylactic acid package retained their firmness during storage, fungal decay was not observed and the weight loss was only $0.8 \%$, whereas the firmness of unpackaged cherries was reduced by $50 \%$ and was not marketable after 21 days.

The continuous changes in retail and distribution practices such as online groceries, the increasing number of conscious consumer, and the socio-economic changes in all around the world have been resulted in significant changes on current consumer demands. The shift of consumer preferences from unpacked to packed food products is a result of these changes.

The consumer preference is changing because of a number of underlying socio-demographic variables. This study describes the consumers' buying behavior and the role of packaging in fruit and vegetable categories for Turkish consumers. Additionally, this study describes the perception of package and waste relationship in these categories. Hence this study can aid marketers in marketing decisions for fresh fruits and vegetables. Moreover, it helps other actors who develope strategies to reduce postharvest waste in fruits and vegetables.

\section{Methodology}

\subsection{Questionnaire description}

An online structured questionnaire was carried out for this study under an Erasmus+ Strategic Partnership for vocational education and training project (Erasmus +, 2017-1-TR01-KA202-045709). Google website was used to design questionnaire. Before the actual implementation of the study started, the questionnaire were pretested and findings of the pre-test were used to get the final version of the questionnaire before launched. The questionnaire was included totally 10 questions. The respondents were asked about their shopping frequency for fresh fruits and vegetables (with scale points: daily, 2-3 times a week, once a week, 2-3 times a month, less than once a month). They also answered a question on choice of packed and loose fruits and vegetables. In this question, the participants were asked How much of the fresh produce they buy is packaged (with scale points: almost no part, less than half, more than half, almost all). In an other question participants were received a list of 10 fresh produce (apple, peach, grape, fig, cherry, strawberry, tomatoes, pepper, carrot, cucumber). Then they were asked "Which fresh fruit or vegetables do they buy as packaged?" and "Which fresh fruit or vegetables would they prefer to buy as packaged".

Participants were asked about their thoughts on the importance of packaged fresh fruits and vegetables. The sociodemographic status such as age, gender, education level and household income of participants were also asked.

\subsection{Data collection and characteristics of survey respondents}

In order to collect the data the respondents were selected as the ones bought fruits and vegetables for the households. The link of online questionnaire were sent to more than 1000 people from urban area via interactive web 2.0 application (whatsapp) and emails. However it was completed by 623 respondents from all around Turkey. The data were obtained during two-month periods with beginning in October 2018 and December 2018.

\subsection{Statistical analysis}

The statistical analysis of collected data were carried out by using the SPSS software (SPSS 15.0, version 2.0, 2006, SPSS Inc., Chicago). Descriptive statistical analysis, cross-tabulation, and frequency

40 | P a g e

www.iiste.org 
distribution were used to figure out the consumers' perception of fresh produce packaging. ANOVA was carried out to determine statistically significant differences between the groups.

\section{Result and Discussion}

\subsection{Socio-demographic profile of respondent}

The distributions of gender, age, education and monthly income of the respondents have been summarized in Table 1 . According to survey results the $61 \%$ of the respondents were women. The largest proportion of respondents $(\% 88.3)$ has had some higher education. 485 of the participants are 30 years old and over. The 44.6 percent of the participants have income of $4500 \mathrm{TL}$ and above.

Table 1. Socio-demographic profile of respondents

\begin{tabular}{|c|c|c|c|}
\hline Characteristic & Distribution (\%) & Characteristic & Distribution (\%) \\
\hline Gender & & Education level & \\
\hline Male & 39 & $\begin{array}{c}\text { Below } \\
\text { intermediate }\end{array}$ & $<1$ \\
\hline Female & 61 & Intermediate & 1.3 \\
\hline Age group & & High school & 9.9 \\
\hline$<18$ years & $<1$ & Graduate & 48.9 \\
\hline $18-29$ years & 21.6 & Postgraduate & 38 \\
\hline $30-41$ years & 44.6 & Monthly Income* & \\
\hline $42-53$ years & 25.5 & Under 1500 TRY & 4.8 \\
\hline $54-65$ years & 6.4 & $1501-3000$ TRY & 13.4 \\
\hline \multirow[t]{3}{*}{$>65$ years } & 1.3 & 3001-4500 TRY & 27.7 \\
\hline & & Above 4501 TRY & 44.6 \\
\hline & & I refuse to answer & 9.5 \\
\hline
\end{tabular}

*1 USD= 5,4357 TRY (Central Bank of The Republic Turkey; Exchange rate on 15th October 2018)

\subsection{Shopping behavior and response on packaging preferences}

In Table 2, the fresh fruits and vegetables purchasing frequency, the portion of fresh produce packaged in total fresh produce purchasing, and which fresh produce are preferred among the packaged ones by respondents were given. As it was seen in Table 2 majority (\%93) of Turkish consumers prefer to purchase fresh fruits and vegetables weekly or more often. As it was expected the fruits and vegetables purchasing frequency coincide with grocery shopping frequency of people because people prefer to save time. The results of the study is consistent with the findings of work done by Popa et al., (2017), which reported that the majority of the people go grocery shopping (87.3\%) weekly or more often $(92.7 \%)$ in Turkey. Eventhough there is a positive shift in consumers perception towards sorted, graded and packaged fruits and vegetables in the world, almost $69 \%$ of respondents still prefer unpackaged fruits and vegetables in Turkey (Table 2). There are different underlying factors on this results but one of them is that the fruits and vegetables are usually sold in loose both in the super/hypermarkets and open market areas in Turkey. There are cultural and traditional differences in buying fresh produce all around the world. For example, more fresh produce is sold in the consumer pack in UK. In France, as a contrast, the selection from a tray or box may be preferred (Commomwelth Secretariat, 2001). In a study in which the Consumers' perception of fruits and vegetable packaging in India has been evaluated by Ali and Kapoor, (2008), it was reported that only $1.4 \%$ of the respondents prefered packed fruits and vegetables. However, In another study the percentage of fresh produce sold loose in UK stores without any primary packaging was reported as $30.7 \%$ (Garnett, 2006). The findings of another study was reported that Scottish people preferred loose and unpacked vegetables or fruits to packed ones (Van Der Pol and Ryan, 1996). Possible reason for this behaviour was explained by the allowance of quality control to be exercised by the consumer in purchasing of such fruit and vegetables. In another study, the Swedish preferrence on packaging aspects of fresh table potatoes were analysed and the common Swedish practice was found to pick their own bulk potatoes "loose" in the shop from a large crate (Fernqvist et al., 2015). Relating to respondents' socio-demographic profiles (gender, age, education level and income), it seemed

41 I P a g e 
that there is no significant differences $(\mathrm{p}>0.05)$ in quantity of fruits and vegetebles that bought as packaged.

Table 2. The distribution of the purchasing frequency, the portion of the packaged ones in total fresh produce and fresh produced preferred in packed

\begin{tabular}{|c|c|c|c|}
\hline \multirow[t]{2}{*}{ Questions } & \multirow[t]{2}{*}{ Options } & \multicolumn{2}{|c|}{$\begin{array}{l}\text { Respondents } \\
\text { reporting }\end{array}$} \\
\hline & & Number & $\%$ \\
\hline \multirow{5}{*}{$\begin{array}{l}\text { Q1:Fresh fruits / vegetables } \\
\text { purchasing frequency }\end{array}$} & Everyday & 8 & 1.28 \\
\hline & 2-3 times per week & 251 & 40.28 \\
\hline & Once a week & 331 & 53.13 \\
\hline & 2-3 times per month & 20 & 3.21 \\
\hline & Less often than once a month & 13 & 2.08 \\
\hline \multirow{4}{*}{$\begin{array}{l}\text { Q2:How much of the fresh produce } \\
\text { you buy is packaged? }\end{array}$} & almost none & 430 & 69.02 \\
\hline & almost all & 13 & 2.08 \\
\hline & less than half & 149 & 23.92 \\
\hline & more than half & 31 & 4.97 \\
\hline \multirow{10}{*}{$\begin{array}{l}\text { Q3: Which fresh fruit or vegetables } \\
\text { do you buy as packaged? }\end{array}$} & Strawberry & 162 & 26.00 \\
\hline & Pepper & 25 & 4.01 \\
\hline & Fig & 100 & 16.05 \\
\hline & Tomatoes & 81 & 13.00 \\
\hline & Carrot & 137 & 21.99 \\
\hline & Grape & 119 & 19.10 \\
\hline & Cherry & 37 & 5.93 \\
\hline & Cucumber & 56 & 8.98 \\
\hline & Apple & 69 & 11.07 \\
\hline & Peach & 49 & 7.86 \\
\hline \multirow{10}{*}{$\begin{array}{l}\text { Q4: Which fresh fruit or vegetables } \\
\text { would you prefer to buy as } \\
\text { packaged? }\end{array}$} & Strawberry & 355 & 56.98 \\
\hline & Pepper & 49 & 7.86 \\
\hline & Fig & 168 & 26.96 \\
\hline & Tomatoes & 93 & 14.93 \\
\hline & Carrot & 44 & 7.06 \\
\hline & Grape & 162 & 26.00 \\
\hline & Cherry & 255 & 40.9 \\
\hline & Cucumber & 62 & 9.95 \\
\hline & Apple & 112 & 17.97 \\
\hline & Peach & 118 & 18.94 \\
\hline
\end{tabular}

Respondents were asked to state their preferences for ten fresh fruits and vegetable items packaged; the results are given in Table 2. For strawberry, 26.00\% of those responding indicated preference for packaged one. The next three fresh produces that bought in package were carrots, grapes and figs with $21.99,19.10$ and $16.05 \%$, respectively. As it is seen from the ranking, consumers generally prefer to buy soft fruits and vegetables in package. However, carrot is one of the unexpected fresh produce which preferred in package due to its rigid structure. The reason would be that the carrot mostly offered to customers as packed in Turkey. Respondents were also asked Which fresh fruit or vegetables would they prefer to buy as packaged (Table 2). The strawberry, cherry, fig, grape and peach were in the first five, respectively, among the 10 fresh produce. This result reveals that the packaging of soft fresh products is more preferred than rigid ones.

\subsection{Respondent beliefs on packaging attributes}

Under this study, the consumer perception on attributes of packaging for fresh produce have been evaluated with a number of statements. The consumers' responses for each statements have been given in Figure 1. The results indicate that among the statement presented, 30\% of the respondents thought that packaging protects the food against impact and $24 \%$ of them thought that the packaging preserves the taste and freshness of fresh produce. The belief of respondents on the protection of fruits and vegetables via packaging could be related with the type of fruit purchased in packaging. Because, as it has seen in answers for Q 3 (Table 2), packed purchased fruits and vegetables are mainly delicate ones 
and these products need the protection during transportation and storage. More than 10 percent of respondents agreed that packaging provides quick purchases. The respondent percentage for the rest of the statements was almost the same and below 10 percent. Surprisingly, only less than $10 \%$ of the respondents consider that packaging could have an effect on the reduction of loss of fruits and vegetables. This could be explained by often food shopping attitudes of respondents and dependently short storage periods of the fruits and vegetables before consumption. So, the packed purchased fruits and vegetables (for example; strawberry) actually consumed in a short time and deterioration is not allowed to cause their loss. When the socio-demographic profiles of the respondent are taken into account there are no significant differences $(p>0.05)$ among the consumers on the key packaging attributes perceived by them. This behaviour of respondents who buy packaged fresh fruits and vegetables might be explained with their similar demographic properties.

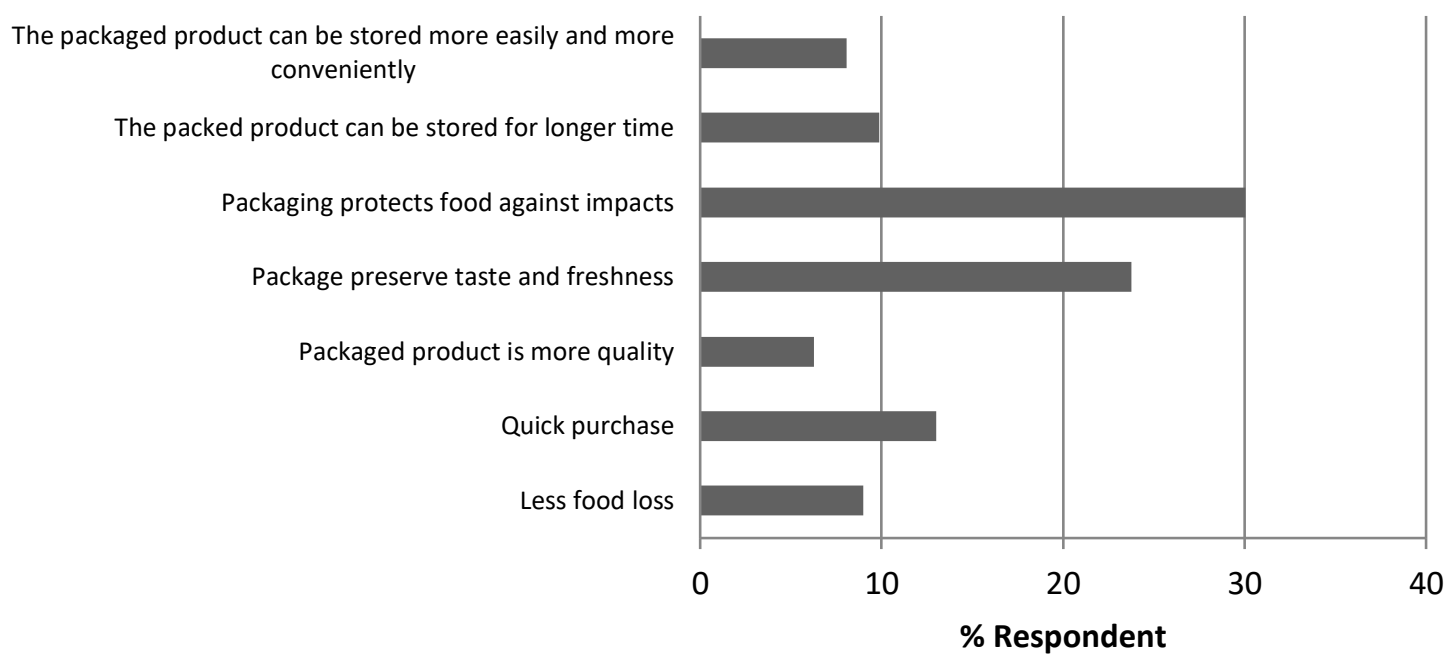

Figure 1. The share of reasons that most important in respondent decision to purchase packaged produce

In order to identify consumers' views, they have been asked to rate their level of agreement or disagreement for two statements which are on the relationship between the packaging and postharvest waste (Table 3). According to the results, while $12.1 \%$ of respondents were undecided, almost $40.5 \%$ of the respondents believe that a portion of fresh produce will be wasted if it is unpackaged. On the other side, only $23.3 \%$ of the respondents agreed that a portion of fresh produce will be wasted if it is packed, while $20.3 \%$ of respondents were undecided.

Table 3. Consumers' views (\%) on relationship between pakaging and waste

\begin{tabular}{lllllc}
\hline Statements & $\begin{array}{l}\text { Strongly } \\
\text { agree }\end{array}$ & Agree & Undecided & Disagree & $\begin{array}{c}\text { Strongly } \\
\text { disagree }\end{array}$ \\
\hline $\begin{array}{l}\text { A part of the packaged } \\
\text { fresh produce I buy is not } \\
\text { consumed and results in } \\
\text { waste }\end{array}$ & 3.5 & 19.8 & 20.3 & 40.9 & 15.1 \\
$\begin{array}{l}\text { A part of the loose fresh } \\
\text { produce I buy is not } \\
\text { consumed and results in } \\
\text { waste }\end{array}$ & 8.2 & 32.3 & 12.1 & 27.6 & 19.4 \\
\hline
\end{tabular}

\section{Conclusion}

The majority of Turkish consumers purchase fresh fruits and vegetables in loose form. The protection function of packaging against impacts was perceived as the most important attribute by the consumers. Results reveal that the packaging of soft fresh produces seems to be more preferred by consumers among 
ten fresh fruits and vegetable items. So, the packaging preference of the repondents and the type of fruit they purchase are very relevant to explain their selection for the importance of packaging as the protection function against impact. In addition, the frequent shopping habits (more than $90 \%$ of respondents purchase fruits and vegetables at least once a week) of Turkish consumers is an important factor behind their attitudes to purchase the fruits and vegetables packed or unpacked. Even if more than half of the respondents are aware of the importance of packaging in reducing the waste for fresh produce, increasing consumers' knowledge on the benefits of the packaging for fresh produce would be effective and impactful to reduce fruit and vegetable postharvest loss.

\section{Acknowledgement}

This study was financially supported by "Best Innovative Approach to Minimize Post Harvest Losses within Food Chain for VET" project (Erasmus +, 2017-1-TR01-KA202-045709) funded by the Erasmus+ Program of the European Union.

\section{References:}

Ali J, Kapoor S \& Pradesh U (2008, June). Consumers' perception on fruits and vegetables packaging in India. In Annual World Symposium of the International Food and Agribusiness Management Association, Monterey, California, USA.

Alturki S (2013) Utilization of Modified Atmosphere Packaging to Extend the Shelf-Life of Fresh Figs. Biotechnology 12(2): 81-86.

Commonwealth Secretariat (2001). Guidelines for Exporters of Fruit and Vegetables to the European Markets.

Fagundes C, Moraes K, Pérez-Gago MB, at al. (2015) Effect of active modified atmosphere and cold storage on the postharvest quality of cherry tomatoes. Postharvest Biology and Technology 109: 73-81.

Frankowska A, Jeswani HK \& Azapagic A (2019) Environmental impacts of vegetables consumption in the UK. Science of The Total Environment 682: 80-105.

Fernqvist F, Olsson A \& Spendrup S (2015) What's in it for me? Food packaging and consumer responses, a focus group study. British Food Journal 117(3): 1122-1135.

Garnett T (2006) Fruit and vegetables \& UK greenhouse gas emissions: exploring the relationship. UK: Food and Climate Research Network, University of Surrey.

Gomiero T, Paoletti MG \& Pimentel D (2008) Energy and environmental issues in organic and conventional agriculture. Critical Reviews in Plant Sciences 27(4): 239-254.

Godfray HCJ, Beddington JR, Crute IR, Haddad L, et al. (2010) Food security: the challenge of feeding 9 billion people. Science 327(5967): 812-818.

Kader AA (2002). Postharvest technology of horticultural crops. University of California Agriculture and Natural Resources.

Kaewklin P, Siripatrawan U, Suwanagul A, et al. (2018) Active packaging from chitosan-titanium dioxide nanocomposite film for prolonging storage life of tomato fruit. International journal of biological macromolecules 112: 523-529.

Kitinoja L (2002) Making the link: Extension of postharvest technology. In: A. A. Kader (Ed.), Postharvest technology of horticultural crops. Oakland, CA: University of California. 
Koutsimanis G, Harte J \& Almenar E (2015) Freshness maintenance of cherries ready for consumption using convenient, microperforated, bio-based packaging. Journal of the Science of Food and Agriculture 95(5): 972-982.

Popa ME, Geicu-Cristea, M Popa, et al. (2017). Consumption and attitudes regarding berries-based products-comparative analysis of Romania, France and Turkey. Romainian Biotechnological Letters, 22(3): 12568-12576.

Ray RC \& Ravi V (2005). Post harvest spoilage of sweetpotato in tropics and control measures. Critical reviews in food science and nutrition, 45(7-8): 623-644.

Rundh B (2005) The multi-faceted dimension of packaging. British food journal. 107(9): 670-684.

Shahnawaz M, Sheikh SA, Soomro AH, et al, (2012) Quality characteristics of tomatoes (Lycopersicon esculentum) stored in various wrapping materials. African Journal of Food Science and Technology 3(5): 123-128.

Van Der Pol M \& Ryan M (1996). Using conjoint analysis to establish consumer preferences for fruit and vegetables. British Food Journal 98(8):5-12 